\title{
SPRING EASTERN SECTIONAL SAMPLER
}

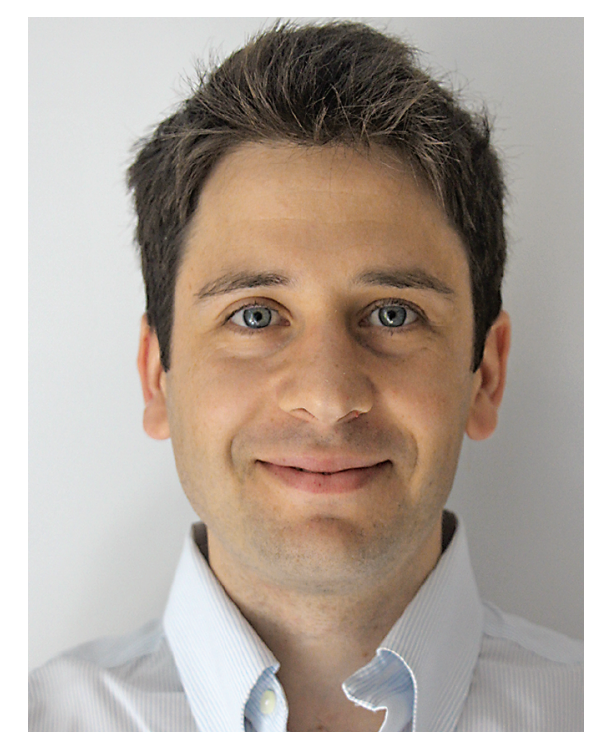

Olivier Bernardi

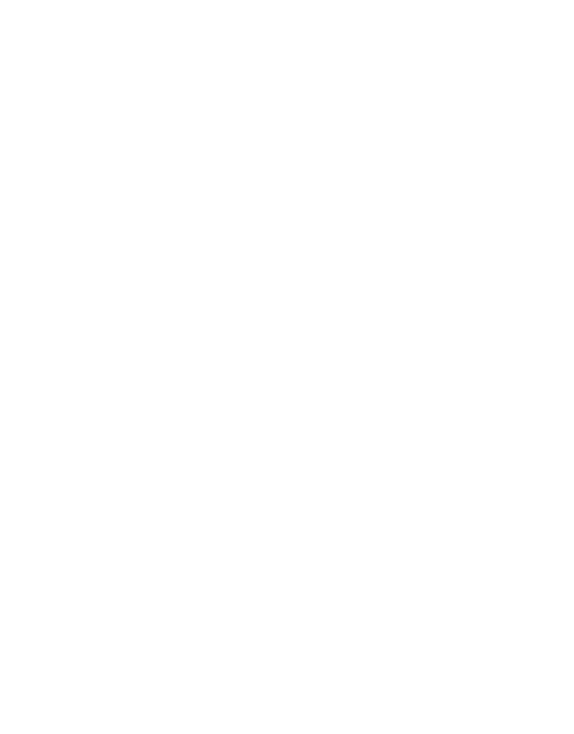

Brian C. Hall

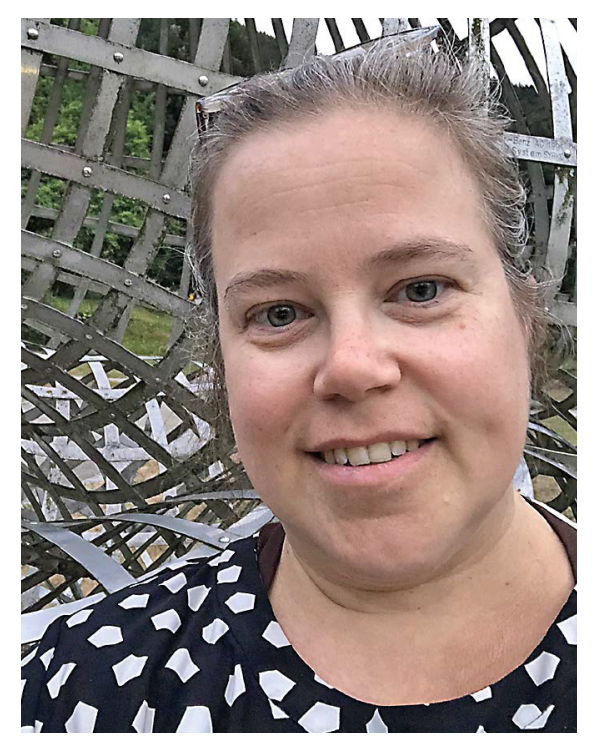

Christina Sormani

In this sampler, all three invited speakers at the AMS Spring Eastern Sectional taking place April 13-14 at University of Connecticut Hartford (Hartford Regional Campus), Hartford, CT, have kindly provided introductions to their Invited Addresses.

Page 566 Olivier Bernardi, Brandeis University

Percolation on Triangulations, and a Bijective Path to Liouville Quantum Gravity

Page 568 Brian C. Hall, Notre Dame University

Eigenvalues of Random Matrices in the General Linear Group in the Large- $N$ Limit

Page 570 Christina Sormani, Lehman College and CUNY Graduate Center

Compactness Theorems for Sequences of Riemannian Manifolds

For permission to reprint this article, please contact: reprint

-permission@ams.org.

DOI: https://dx.doi.org/10.1090/noti 1845 